\title{
Effects of postnatal alcohol exposure on maternal nesting behavior in the rat
}

\author{
NIGEL W. BOND \\ School of Behavioural Sciences, Macquarie University, North Ryde, N.S.W. 2113, Australia
}

\begin{abstract}
Seven female Wistar rats were fed a liquid diet containing Sustagen and ethanol through Days 1-17 of lactation. Six control females were pair-fed an identical liquid diet except for isocaloric substitution of sucrose for ethanol. Continuous monitoring of maternal nesting behavior, employing automated nesting chambers, indicated that the mothers fed ethanol spent more time on the nest nursing their young than the pair-fed controls during the middle of the observation period. This increase in nesting time may be due to a decrease in activity in the ethanol-fed mothers or due to greater heat loss in their pups, allowing them to remain longer on the nest. This increased nesting time occurs when the pups' motor effectiveness and exploratory drive are developing, and may account for the long-term behavioral changes seen in the pups.
\end{abstract}

It has now been clearly demonstrated that a variety of treatments, including drugs, malnutrition, and stress, imposed on the neonatal organism can have profound and permanent effects on subsequent behavioral and physiological processes (Gottlieb, 1978). Despite this, very little is known about the effects of alcohol on the developing organism (Hollstedt, Olsson, \& Rydberg, 1977). Recently, it has been reported that the offspring of chronic alcoholic women exhibit a distinct pattern of craniofacial, limb, and cardiovascular defects associated with growth deficiencies and mental retardation (Jones, Smith, Ulleland, \& Streissguth, 1973). Following the discovery of this "fetal alcohol syndrome," there has been an increase of interest in the effects of prenatal alcohol exposure on offspring behavior, but the same enthusiasm has not encompassed the study of the effects of alcohol on the neonatal organism. This is important, because much research into the fetal alcohol syndrome has employed the rat and the mouse as possible models. Both of these animals differ from man in that their whole brain growth spurts are postnatal, whereas in man the spurt is perinatal (Dobbing \& Smart, 1973). Therefore, if one is interested in the effects of alcohol during the period of maximal brain growth, one should study the postnatal period in the rat and the mouse.

Very few studies have restricted alcohol exposure to the postnatal period. However, those that have seem to indicate that the effects of alcohol on the neonatal organism are at least as profound as the

This research was supported by a Macquarie University research grant. Thanks are due to the "Workshop" for constructing the nesting boxes and to Len Glue for his valuable technical assistance. Reprints may be obtained from the author at the above address. effects on the fetus. Thus, exposure during the postnatal period leads to higher infant mortality, growth retardation, and developmental delays (Martin, Martin, Sigman, \& Radow, 1977), emotional reactivity (Abel, 1975), and learning deficits in rats (Bond, Note 1), increased seizure susceptibility (Yanai \& Ginsburg, 1976), and decreases in aggressive behavior in C57 and DBA mice (Yanai \& Ginsburg, 1977). Further, Bauer-Moffett and Altman (1977) have demonstrated that rats exposed to alcohol postnatally evidence retarded growth in a variety of brain regions, and Rawat (1975) has observed that pups suckling on ethanol-fed mothers had significantly lower levels of cerebral DNA and RNA.

Given that alcohol occurs in the breast milk in concentrations higher than in the mother's blood (Matzdorff, 1942) and that it is excreted in the milk (Lehman, Schwerma, \& Rickards, 1945), it would seem reasonable to attribute the physical and behavioral changes observed to the alcohol treatment per se. However, it is also possible that the observed effects of the alcohol were mediated via changes in maternal behavior (Abel, 1975; Yanai \& Ginsburg, 1977). There is evidence that exposure to ethanol can depress the milk-ejection reflex in nursing mothers through the inhibition of oxytocin release (Fuchs, 1969). Thus, the ethanol treatment may also affect the nursing behavior of the mother rats. For example, Baer and Crumpacker (1977) have reported increased cannibalism in the mothers of long-sleep (LS) mice forced to drink alcohol during lactation, and have suggested that part of the effect of the drug on progeny survival is due to deleterious alterations in maternal care behavior. Given the profound influence of the early environment on offspring behavior, such an alteration in the mother-pup interaction might account for the long-term changes seen in the pups' behavior (Denenberg, 1964). 
The present experiment compared both the number of nesting bouts and the cumulative nesting time of nursing dams fed ethanol and pair-fed controls. This was achieved by employing automated nesting boxes which allowed for the continuous monitoring of maternal nesting behavior (Croskerry, Smith, Leon, \& Mitchell, 1976).

\section{METHOD}

\section{Subjects and Apparatus}

Thirteen 100-day-old pregnant Wistar rats were used. They were housed individually in plastic cages, measuring $23 \times 38 \times$ $15 \mathrm{~cm}$, in a sound-attenuated temperature-controlled room on a 12-h light-dark cycle with lights on at $0600 \mathrm{~h}$. Each of the cages contained a nest-tray designed for continuous monitoring of maternal nesting behavior. These recording cages were described in detail by Croskerry et al. (1976). Briefly, each tray was balanced on a fulcrum, and when the female entered the nest-tray, a microswitch closed and activated an event recorder pen. This enabled a complete record of maternal nesting times to be obtained. Further, the dimensions of the nests were such $\left(136 \mathrm{~cm}^{2}\right)$ that nesting time also provided an accurate estimate of nursing time (cf. Croskerry et al., 1976).

\section{Procedure}

On the day of birth, the litters were culled to six pups per dam. The experimental group $(\mathrm{N}=7)$ received a liquid diet containing $6.5 \%$ ethanol $(95 \% \mathrm{v} / \mathrm{v}), 3 \%$ sucrose $(87 \% \mathrm{w} / \mathrm{v}), 87.5 \%$ Sustagen $(.95 \mathrm{cal} / \mathrm{ml})$, and $3 \%$ water. The control group $(\mathrm{N}=6)$ was pairfed an identical liquid diet except for the isocaloric substitution of sucrose for the ethanol. The diets were prepared fresh daily and presented in a graduated Richter tube inserted into the side of the cage opposite the entrance to the nesting box. Thus it could not be reached unless the female left the nest. The dams were fed their respective diets for Days 1-17 after parturition, when the experiment was terminated. The average dose of ethanol consumed daily by each experimental dam was $12.2 \mathrm{~g} / \mathrm{kg}$. A pup was lost from each of two experimental litters and from one control litter.

\section{RESULTS}

Figure 1A shows the mean total nest times for both groups on each day. Nesting times were analyzed using a two-way analysis of variance. This yielded a significant effect of Time $(F=216.8, d f=16 / 176$, $\mathrm{p}<.001)$ and a Diet by Time interaction $(\mathrm{F}=2.8$, $\mathrm{df}=16 / 176, \mathrm{p}<.001)$. Further analyses revealed both linear $(\mathrm{F}=685.1, \mathrm{df}=1 / 11, \mathrm{p}<.001)$ and quadratic trends $(\mathrm{F}=14.0, \mathrm{df}=1 / 11, \mathrm{p}<.01)$ on the Trials factor. The Diet by Trials interaction was restricted to a quadratic trend $(F=14.1$, df $=$ $1 / 11, p<.01)$. Inspection of Figure $1 \mathrm{~A}$ reveals that, while both groups evidenced a progressive decline in daily nest time postpartum, the alcohol group spent significantly more time in the nesting boxes with their pups during the middle of the nursing period.

Nesting bouts are illustrated in Figure 1B. A twoway analysis of variance yielded only a significant effect of Time $(F=6.5$, df $=16 / 176, p<.001)$, both groups evidencing fewer nesting bouts during the middle of the observation period.
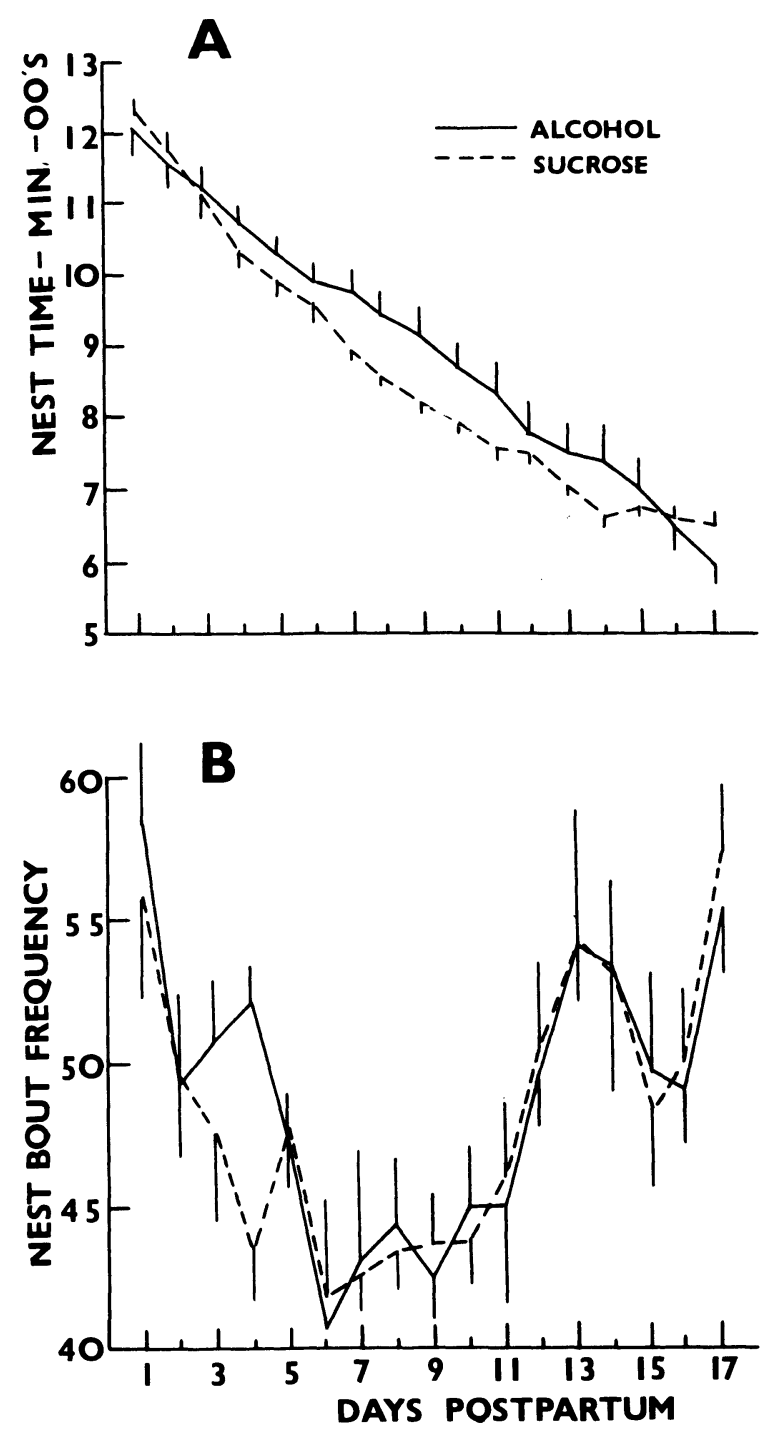

Figure 1. (A) Mean total daily nest time of the alcohol-fed and sucrose-fed mother rats. (B) Mean daily nest bout initiation frequencies (SEMs are indicated by the vertical lines.)

The weights of the alcohol and control mothers and their litters did not differ throughout the experiment $(F<1.0$, in both cases).

\section{DISCUSSION}

The maternal nesting pattern of both groups evidenced a progressive decline in daily nest time over the course of the lactation period (Figure 1A). Interestingly, this decline in nest time did not result from a decrease in the number of nesting bouts, which actually increased towards the end of the study (Figure 1B), but from a decrease in the length of each bout. In this respect, the present results replicate previous findings employing automated nesting chambers (Leon, Croskerry, \& Smith, 1978). 
Importantly, the mothers fed ethanol spent more time on the nest nursing their young than the pairfed controls, although this difference was restricted to the middle of the nursing period. There are a number of possible reasons for this behavioral difference. First, it is well known that large doses of ethanol can depress activity (Pohorecky, 1977). Thus, the females fed ethanol may have been less active and spent more time lying on the nest as a result. Second, Leon et al. (1978) have shown that nest bout durations are normally limited by a rise in maternal temperature brought about by huddling with the litter. Ethanol is known to cause vasodilation and heat loss (Ritchie, 1965). Therefore, the experimental pups, having consumed ethanol via their mother's milk, may lose heat more quickly than the control pups. If the experimental litters were colder than the controls at the beginning of the nesting bouts, then their mothers would be able to remain with them for longer periods. (Note that the two groups did not differ in the number of nesting bouts, only in the nesting time per bout, experimental mothers displaying longer bouts.)

The fact that the nursing mothers fed ethanol spent more time with their young during the middle of the nursing period is particularly interesting, because, from about the 10th day of life, the rat displays a steady growth in motor effectiveness and development of the exploratory drive (Altman \& Sudarshan, 1975). Thus, the change in the experimental mothers' nursing behavior occurs at a time when it may have a profound influence on pup development and may account for the long-term behavioral changes seen in the pups (Denenberg, 1964). However, the automated nesting boxes employed in the present study do not allow for the observation of a variety of maternal and pup behaviors. Clearly, further work is needed to determine if the observed changes in nursing behavior influence pup development in any way.

The increased nesting times of the experimental dams may have an important effect on the growth of their offspring. As noted previously, exposure to ethanol can depress the milk-ejection reflex in nursing mothers and lead to weight loss in their pups (Martin et al., 1977). The pair-feeding technique employed in the present study was successful in matching the weights of both groups of nursing mothers and their litters despite the fact that the daily dose of ethanol consumed by the experimental mothers, $12.2 \mathrm{~g} / \mathrm{kg}$, was well within the range required to produce interference with milk ejection (Fuchs, 1969). If this was the case, it is possible that the increased nesting time of the experimental dams may have allowed their pups to compensate for any impairment in the milk-ejection reflex by increasing the suckling time available to them.

In conclusion, the present results indicate that postnatal ethanol exposure leads to increases in maternal nesting time, which may account for some of the long-term behavioral changes seen in the pups.

\section{REFERENCE NOTE}

1. Bond, N. W. Postnatal alcohol exposure in the rat: Its effects on avoidance conditioning, Hebb-Williams maze performance, maternal behavior and pup development. Manuscript in preparation.

\section{REFERENCES}

Abel, E. L. Emotionality in offspring of rats fed alcohol while nursing. Journal of Studies on Alcohol, 1975, 36, 654-658.

Altman, J., \& Sudarshan, K. Postnatal development of locomotion in the laboratory rat. Animal Behaviour, 1975, 23, 896-920.

Baer, D. S., \& Crumpacker, D. W. Fertility and offspring survival in mice selected for different sensitivities to alcohol. Behavior Genetics, 1977, 7, 95-103.

Bauer-Moffett, C., \& Altman, J. The effect of ethanol chronically administered to pre-weanling rats on cerebellar development. Brain Research, 1977, 119, 249-268.

Croskerry, P. G., Smith, G. K., Leon, L. N., \& Mitchell, E. A. An inexpensive system for continuously recording maternal behavior in the laboratory rat. Physiology \& Behavior, 1976, 16, 223-225.

Denenberg, V. H. Critical periods, stimulus input and emotional reactivity: A theory of infantile stimulation. Psychological Review, 1964, 71, 335-351.

Dobbing, J., \& SmarT, J. L. Early undernutrition, brain development and behavior. In S. A. Barnett (Ed.), Ethology and development. London: Heinemann, 1973.

Fuchs, A. R. Ethanol and the inhibition of oxytocin release in lactating rats. Acta Endocrinologica (Kobehavn), 1969, 2, 546-554.

Gottlieb, G. (Ed.), Early influences. New York: Academic Press, 1978.

Hollstedt, C., Olsson, O., \& Rydberg, U. The effect of alcohol on the developing organism. Medical Biology, 1977, $55,1-14$.

Jones, K. L., Smith, D. W., Ulleland, D. N., \& Streissguth, A. P. Pattern of malformation in offspring of chronic alcoholic mothers. Lancet, 1973, 1, 1267-1271.

Lehman, A. J., Schwerma, H., \& Rickards, E. Iso propyl alcohol: Acquired tolerance in dogs, rate of disappearance from blood stream in various species and effects on successive generations of rats. Journal of Pharmacology and Experimental Therapeutics, 1945, 85, 61-69.

Leon, M., Croskerry, P. G., \& Smith, G. K. Thermal control of mother-young contact in rats. Physiology \& Behavior, 1978, 21, 793-811.

Martin, J. C., Martin, D. C., Sigman, G., \& Radow, B. Offspring survival, development and operant performance following maternal ethanol consumption. Developmental Psychobiology, 1977, 10, 435-446.

MatzdorfF, F. Ist der Verlauf der Alcoholkurve in der Milch stillender Frauen von der Milchbildung und Milchausscheidung abhangig? Klinische Wschr., 1942, 21, 131.

Poнorecky, L. A. Biphasic action of ethanol. Biobehavioral Reviews, 1977, 1, 231-240.

RAWAT, A. K. Ribosomal protein synthesis in the fetal and neonatal brain as influenced by maternal ethanol consumption. Research Communications in Chemical Pathology and Pharmacology, 1975, 12, 723-732.

RITchie, J. M. The aliphatic alcohols. In L. S. Goodman \& A. Gilman (Eds.), The pharmacological basis of therapeutics. New York: Macmillan, 1965.

YanAI, J., \& GinsBURG, B. E. Audiogenic seizures in mice whose parents drank alcohol. Journal of Studies on Alcohol, 1976, 37, 1564-1571.

YanAI, J., \& Ginsburg, B. E. Long term reduction of male agonistic behavior in mice following early exposure to ethanol. Psychopharmacology, , 1977, 52, 31-34.

(Received for publication October 22, 1979; accepted November 12,1979.) 